\title{
Public health implications of milk fats: the current evidence base and future directions
}

Article

Accepted Version

Markey, O., Hobbs, D. and Givens, I. (2015) Public health implications of milk fats: the current evidence base and future directions. Clinical Lipidology, 10 (1). pp. 5-8. ISSN 1758-4299 doi: https://doi.org/10.2217/CLP.14.66 Available at https://centaur.reading.ac.uk/39444/

It is advisable to refer to the publisher's version if you intend to cite from the work. See Guidance on citing.

To link to this article DOI: http://dx.doi.org/10.2217/CLP.14.66

Publisher: Future Medicine

All outputs in CentAUR are protected by Intellectual Property Rights law, including copyright law. Copyright and IPR is retained by the creators or other copyright holders. Terms and conditions for use of this material are defined in the End User Agreement.

www.reading.ac.uk/centaur

\section{CentAUR}


Central Archive at the University of Reading

Reading's research outputs online 
Public health implications of milk fats: the current evidence base and future directions

Oonagh Markey, Ditte A. Hobbs, David I. Givens

\section{Oonagh Markey}

Author for correspondence:

Hugh Sinclair Unit of Human Nutrition, Department of Food and Nutritional Sciences, University of Reading, Reading, RG6 6AP, UK.

Tel: +44 1183787734

o.markey@reading.ac.uk

\section{Ditte A. Hobbs}

Hugh Sinclair Unit of Human Nutrition, Department of Food and Nutritional Sciences, University of Reading, Reading, RG6 6AP, UK.

\section{David I. Givens}

Food Production and Quality Research Division, Faculty of Life Sciences, The University of Reading, Reading RG6 6AR, UK.

Keywords: cardiovascular disease risk, milk fat, saturated fatty acids, dairy consumption 


\section{Introduction}

With cardiovascular disease (CVD) recognised as a leading cause of morbidity and mortality in the UK, the contribution of major modifiable risk factors, such as diet, are becoming increasingly more important in CVD prevention. A high saturated fatty acid (SFA) intake is associated with an increased risk of coronary heart disease (CHD) and for this reason key public health advice recommends that SFA should contribute less than $10 \%$ of total energy (TE) [1] . However UK adults are currently exceeding this recommendation, with SFA intake accounting for $12 \%$ of TE [2]. Therefore, there is a need for novel interventions to help reduce or replace the amount of SFA in the diet. In comparison to substitution with carbohydrates, evidence suggests that replacement of SFAs with unsaturated fatty acids (FA) may provide a greater CVD risk reduction [3]. Indeed, lowering intake of SFA, through modification of FA profile of the diet, as opposed to reduction in its total fat content, may reduce cardiovascular events by up to $14 \%$ [3], which could have a major impact on public health.

This article will present the current prospective evidence on milk and milk-derived foods in relation to CVD events. The potential of ruminant feeding-based public health strategies aimed at reducing cardiovascular risk markers, through replacement of SFA in milk fat with unsaturated FAs, will also be discussed.

\section{Nutrient composition of milk and dairy foods}

Ruminant milk is nutrient dense and is a key source of energy, protein and micronutrients such as calcium, phosphorus, potassium, iodine and vitamin D [4,5]. Consequently, reducing dairy consumption, as a means of lowering SFA intake, could lead to inadequate intake of these nutrients, especially in vulnerable infant and elderly populations.

Additionally, other nutrients found in the diary matrix may be cardio-protective. Calcium and milk proteins (whey and casein) are linked to the blood pressure regulatory properties of dairy; it is believed that protein-derived bioactive peptides have a role to play in the anti-hypertensive aspects of dairy, in part, through inhibition of the angiotensin-Iconverting enzyme mechanism [5]. When compared with the intake of their industrially produced counterparts, ruminant trans fatty acids (rTFA) do not appear to have the negative effects on CVD risk, with some studies inferring that their intake may be associated with reduced cardiovascular risk $[4,5]$. It is recognised that rTFA are consumed at very small quantities but research is needed to clarify whether increasing rTFA intake, through manipulation of the fatty acid profile of dairy products, affects cardio-metabolic health. 
While there are some limited data which suggest that the consumption of milk-derived conjugated linoleic acid (CLA) may be associated with beneficial cardio-protective effects, more conclusive evidence is needed to fully understand the impact of CLA on CVD risk outcomes [6].

\section{Contribution of milk to saturated fat intake}

Milk and dairy products (excluding butter and composite dairy dishes) contribute to almost one quarter of SFA intake the UK diet [7] . A large portion of energy in milk is derived from fat, with SFA accounting for approximately $70 \%$ of total milk fat, predominantly in the form of myristic (C14:0), palmitic (C16:0) and stearic (C18:0) acids. As a result of their major contribution to SFA intake, it has been perceived that the consumption of milk and milkderived products should be limited as a means of reducing the risk of CVD. However, there is good evidence of the contrary, as will be explored further in this article.

\section{Milk and cholesterol levels}

While it is recognised that the effect of SFA on CVD is linked to increases in serum lipids, predominantly LDL-cholesterol (LDL-C), some intervention studies have revealed that milk or dairy fat feeding does not significantly increase this risk marker for CVD and cross-sectional evidence suggests that FAs associated with dairy fat intake may have a beneficial effect on LDL-C particle size distribution; however these findings require further investigation (see [5]). Furthermore, it is recognised that there is a differential effect of dairy product type on CVD risk factors, such that fermented dairy products may have a more favourable effect on blood lipid profiles than intake of butter, matched for fat and SFA content [8]. Although limited data are available, it is hypothesised that the higher calcium content of the cheese may lead to a reduced fat absorption when compared to butter, probably through the intestinal formation of insoluble FA calcium soaps [8].

\section{Prospective evidence on milk/dairy foods and cardiovascular disease}

There have been a number of overviews published on the relationship between consumption of milk and dairy foods and CVD. To date, the largest was a meta-analysis based on 38 cohort studies [9]. This meta-analysis with the addition of data from six recently published studies (see [10] for details) showed that the overall relative risk (RR) for CHD was 0.92, suggesting a reduction of about $8 \%$ in those subjects who reported the highest milk/dairy intake, compared with subjects with the lowest intake (17 studies RR: $0.92 ; 95 \% \mathrm{CI}, 0.86-$ 
0.99). This meta-analysis also showed that a higher milk/dairy intake was related to a $19 \%$ lower risk of stroke (12 studies RR: $0.81 ; 95 \%$ CI, 0.71-0.92). Five studies reported on risk of haemorrhagic strokes (RR: $0.75 ; 95 \% \mathrm{CI}, 0.60-0.94$ ) and three studies on subarachnoid bleeds (RR 0.93; 95\% CI, 0.84-1.02) and these studies suggested a $25 \%$ and $7 \%$ reduction in risk with the highest milk/dairy intake for haemorrhagic strokes and subarachnoid bleeds, respectively [10].

In line with the aforementioned, meta-analysis evidence from prospective cohort studies show no association between individual dairy foods and CHD risk [11-15], except for an inverse association between cheese consumption and risk of myocardial infarction [16], and between low-fat milk and incident CHD [17]. In relation to stroke, the findings were inconsistent, with several studies showing a significant inverse association with low-fat milk [17], low-fat dairy [18] and fermented dairy products $[17,19]$, whereas in four other studies the consumption of specific dairy foods was not related to stroke $[12,13,15,20]$.

Overall, the evidence from prospective cohort studies shows that milk/dairy consumption does not increase CVD risk. Conversely, individuals with the highest milk/dairy intake had the lowest risk of CVD. However, the effects of individual dairy foods such as butter and cheese, as well as benefits of fat-reduced milk and SFA-reduced milk are less certain.

\section{Modification of the fatty acid profile of ruminant milk}

Although some argue that the nutrients within the dairy food matrix may act synergistically with SFA to prevent the onset of CVD, the potential additional cardio-protective benefits of replacing milk SFA with cis-MUFA or cis-PUFA, through dietary supplementation of the bovine diet with oil seeds or plant oils (typically rich in C18 MUFA and/or PUFA), needs to be further explored $[4,5]$. Supplementation of the diet with oils that are rich in long chain unsaturated FA reduces the mammary gland synthesis of short- and medium chain SFA (C6:0-C16:0) and subsequently increases long-chain FA profile of the milk $[4,5]$. Additionally, this strategy has the added benefit of removing SFA from the food chain, whilst maintaining the valuable contribution that milk makes to macro- and micronutrient intake.

\section{Modified saturated fat-reduced dairy consumption and cardiovascular disease risk}

There is a scarcity of randomised controlled trial data that has examined the impact of consuming saturated fat-reduced, unsaturated fat-rich modified milk and dairy products on 
97 CVD risk. Although the limited research suggests that intake of modified dairy products may favourably impact on CVD risk markers, an inherent limitation of these studies was a reliance on fasting circulating lipid levels as a biomarker for CVD risk (for detailed review, see [5]). Given the aforementioned complexity of the structural properties of milk, and considering that humans spend the majority of their time in the postprandial state, future research needs to provide a more meaningful holistic evaluation and examine the impact of modified dairy consumption on a variety of risk factors linked to the pathophysiology of CVD including endothelial function, arterial stiffness, postprandial lipaemia and inflammatory biomarkers [4].

The University of Reading is contributing to this fundamental research gap by conducting a UK Medical Research Council-funded project called the RESET (REplacement of SaturatEd fat in dairy on Total cholesterol) study; it is testing the hypothesis that modified dairy products (milk, cheese and butter), which have a substantial proportion of SFA replaced with cis-MUFA, will improve vascular function, reduce inflammatory markers and other risk markers for CVD relative to matched commercially available products in both chronic and acute within chronic settings (ClinicalTrials.gov NCT02089035). Findings from the RESET intervention study (anticipated to be completed in December 2015), will help to elucidate if reducing the SFA content of dairy products is beneficial to numerous components of cardiovascular health and may have potential for improving the overall health of the population.

\section{Conclusion}

Milk and milk-derived products are complex, nutrient dense foods but there is some concern that their intake could increase risk of CVD. Despite the significant SFA profile of milk fat, epidemiological evidence and experimental data challenge this perception. Indeed, these data suggest that milk may afford some protection from cardiovascular events, but the evidence is less substantial for other dairy products. There is a need to carry out welldesigned, human dietary intervention studies to determine whether consumption of modified milk and dairy products, with an unsaturated FA enhanced profile, may provide more protection from CVD in both healthy and at-risk populations. 
The authors have no relevant affiliations or financial involvement with any organization or entity with a financial interest in or financial conflict with the subject matter or material discussed in the manuscript. This includes employment, consultancies, honoria, stock ownership or options, expert testimony, grants or patents received or pending, or royalties. No writing assistance was utilized in the production of this manuscript.

\section{References}

1. Department of Health: Dietary Reference Values for Food Energy and Nutrients for the United Kingdom. London: Her Majesty's Stationery Office. 41: Report on Health and Social Subjects., (1991).

2. Bates B, Lennox A, Prentice A, Bates C, Swan G: National Diet and Nutrition Survey: Headline Results from Years 1, 2 and 3 (combined) of the Rolling Programme 2008/09-2010/11

http://webarchive.nationalarchives.gov.uk/20130402145952/http://transparency.dh. gov.uk/2012/07/25/ndns-3-years-report/ (accessed Oct 2014). (2012).

3. Hooper $L$, Summerbell $C D$, Thompson $R$ et al:: Reduced or modified dietary fat for preventing cardiovascular disease. Cochrane Database of Systematic Reviews 16(5), (2012).

4. Markey O, Vasilopoulou D, Givens DI, Lovegrove JA: Dairy and cardiovascular health: Friend or foe? Nutrition Bulletin 39(2), 161-171 (2014).

5. Givens DI: Milk in the diet: good or bad for vascular disease? Proceedings of the Nutrition Society 71(01), 98-104 (2012).

6. Dilzer A, Park Y: Implication of conjugated linoleic acid (CLA) in human health. Critical Reviews in Food Science and Nutrition 52(6), 488-513 (2012).

7. Bates B, Lennox A, Prentice A, Bates C, Swan G: Department of Health: National Diet and Nutrition Survey: Headline results from Years 1 and 2 (combined) of the rolling programme 2008/9 - 2009/10.

https://www.gov.uk/government/uploads/system/uploads/attachment data/file/207708/ND NS-Y3-report All-TEXT-docs-combined.pdf (accessed November 2014). (2011).

8. Huth PJ, Park KM: Influence of Dairy Product and Milk Fat Consumption on Cardiovascular Disease Risk: A Review of the Evidence. Advances in Nutrition 3(3), 266-285 (2012). 
9. Elwood PC, Pickering JE, Givens DI, Gallacher JE: The consumption of milk and dairy foods and the incidence of vascular disease and diabetes: an overview of the evidence. Lipids 45(10), 925-939 (2010).

10. Givens DI, Livingstone KM, Pickering JE, Fekete ÁA, Dougkas A, Elwood PC: Milk: White elixir or white poison? An examination of the associations between dairy consumption and disease in human subjects. Animal Frontiers 4(2), 8-15 (2014).

11. Goldbohm RA, Chorus AMJ, Garre FG, Schouten LJ, Van Den Brandt PA: Dairy consumption and 10-y total and cardiovascular mortality: a prospective cohort study in the Netherlands. American Journal of Clinical Nutrition 93(3), 615-627 (2011).

12. Louie JC, Flood VM, Burlutsky G, Rangan AM, Gill TP, Mitchell P: Dairy consumption and the risk of 15-year cardiovascular disease mortality in a cohort of older Australians. Nutrients 5(2), 441-454 (2013).

13. Kondo I, Ojima T, Nakamura M et al.: Consumption of Dairy Products and Death From Cardiovascular Disease in the Japanese General Population: The NIPPON DATA80. Journal of Epidemiology 23(1), 47-54 (2013).

14. Soedamah-Muthu SS, Verberne LD, Ding EL, Engberink MF, Geleijnse JM: Dairy consumption and incidence of hypertension: a dose-response meta-analysis of prospective cohort studies. Hypertension 60(5), 1131-1137 (2012).

15. Dalmeijer GW, Struijk EA, Van Der Schouw YT et al:: Dairy intake and coronary heart disease or stroke--a population-based cohort study. International Journal of Cardiology 167(3), 925-929 (2013).

16. Patterson $E$, Larsson SC, Wolk A, Akesson A: Association between dairy food consumption and risk of myocardial infarction in women differs by type of dairy food. Journal of Nutrition 143(1), 74-79 (2013).

17. Sonestedt E, Wirfalt E, Wallstrom P, Gullberg B, Orho-Melander M, Hedblad B: Dairy products and its association with incidence of cardiovascular disease: the Malmo diet and cancer cohort. European Journal of Epidemiology 26(8), 609-618 (2011).

18. Larsson SC, Virtamo J, Wolk A: Dairy consumption and risk of stroke in Swedish women and men. Stroke 43(7), 1775-1780 (2012).

19. Goldbohm RA, Chorus AM, Galindo Garre F, Schouten LJ, Van Den Brandt PA: Dairy consumption and 10-y total and cardiovascular mortality: a prospective cohort study in the Netherlands. American Journal of Clinical Nutrition 93(3), 615-627 (2011).

20. Bernstein AM, Sun Q, Hu FB, Stampfer MJ, Manson JE, Willett WC: Major dietary protein sources and risk of coronary heart disease in women. Circulation 122(9), 876-883 (2010). 
